\title{
¿Disminuye la eficacia o la seguridad de las vacunas frente a la COVID-19 en los pacientes con dolor crónico?
}

\author{
Does it decrease the efficacy or safety of COVID-19 \\ vaccines in patients with chronic pain?
}

\author{
I. Failde Martínez \\ Catedrática de Medicina Preventiva y Salud Pública. Universidad de Cádiz, España
}

Desde hace aproximadamente un año y medio, estamos sufriendo los efectos de la pandemia producida por el SARS-CoV-2. Durante este tiempo, los avances en el conocimiento sobre el virus, la enfermedad y sus consecuencias, así como sobre los posibles tratamientos, han sido enormes. De la misma manera, la velocidad en el desarrollo de las vacunas y la demostración de su eficacia y seguridad, esencialmente en sujetos sanos, han puesto en evidencia la importancia de la investigación. Sin embargo, a pesar de todos los avances, aún existen cuestiones que se plantean en la práctica clínica que están por resolver y que son objeto de investigación y debate. Uno de los temas que surgen es la efectividad de las vacunas en determinadas circunstancias clínicas, o en ciertos grupos de pacientes, como son los trasplantados, inmunocomprometidos, o aquellos sujetos con dolor crónico que están en tratamiento con AINE o corticoides.

Estudios previos han mostrado que los AINE, comúnmente utilizados en pacientes con dolor, pueden tener efectos significativos en la inhibición de los linfocitos B humanos y la síntesis de lgM e lgG. También se ha mostrado una relación directamente proporcional entre el aumento de las dosis de AINE y la reducción de la producción de inmunoglobulinas, y se ha descrito que los AINE ejercen efectos inmunomoduladores al interferir con la activación, proliferación y síntesis de citoquinas, de monocitos y de linfocitos T humanos (1). Sin embargo, los datos no son concluyentes y suficientemente robustos como para sacar conclusiones significativas y cambiar los posibles algoritmos de práctica.

De la misma manera, y en lo que respecta a los corticoides, ha surgido la pregunta de si el tratamiento con esteroides tiene un efecto negativo sobre la eficacia de las vacunas frente a la COVID-19 en los pacientes con dolor crónico. Chakravarthy y cols. [르 en un estudio en el que se analiza el efecto y la seguridad de las vacu- nas Pfizer-BioNTech y Moderna en pacientes con dolor crónico a los que se les han administrado corticoides vía epidural, concluyen que no se ha demostrado que estos fármacos administrados sistémicamente en forma de bolo afecten la eficacia ni la seguridad de estas vacunas, y no hay evidencias que sugieran que estos tratamientos deban postponerse o evitarse debido a la vacunación frente a la COVID-19. Los autores matizan que, a la hora de decidir sobre esta cuestión, habría que considerar los riesgos individuales de los pacientes al modificar los planes de tratamiento del dolor, incluidas las estrategias de dosificación, la selección de esteroides y el momento del tratamiento, así como valorar la coexistencia de otros procesos causantes de inmunosupresión.

Más recientemente, la revista Pain Medicine, en línea con lo anterior, publicó un artículo sobre el efecto que la administración epidural e interarticular de corticoides en pacientes con dolor crónico tiene sobre la eficacia de las vacunas frente a la COVID-19 que utilizan un adenovirus como vector, en concreto sobre las vacunas de Astra-Zeneca y Janssen (프). En este trabajo los autores reconocen la necesidad de más estudios que analicen el efecto de los corticoides sobre la inmunidad adquirida por la vacunación, que había sido cuestionado esencialmente basándose en los resultados de un estudio realizado con la vacuna de la influenza, donde se muestra una menor eficacia vacunal cuando se utilizan corticoides (4). Asimismo, exponen el efecto supresor de entre 1 a 4 semanas de la administración de corticosteroides sobre el eje hipotálamo-hipofisario, tanto con la administración epidural como intrarticular, incluso a dosis bajas (triamcinolona $20 \mathrm{mg}$ ). Debido a ello, dada la cronología de la eficacia notificada de estas vacunas $[2$ semanas después de la administración de la vacuna Janssen y 15 días después la segunda dosis de la vacuna AstraZeneca), los autores recomiendan que, siempre que sea posible, se debe considerar el momento 
de la administración electiva de corticosteroides no menos de 2 semanas antes y no menos de 2 semanas después de la administración de una dosis de vacunas frente a COVID-19 basadas en vectores de adenovirus. Estos autores también refieren que, a pesar de que podrían existir diferencias en el periodo de seguridad para las vacunas de ARNm, en aras de simplificar los protocolos se mantiene la misma recomendación también con estas vacunas.

A la vista de la información que conocemos hasta ahora, parece razonable pensar que los pacientes que sufren dolor crónico no van a ver afectada de manera considerable la inmunidad adquirida por la vacunación como consecuencia de su tratamiento para el dolor, sin embargo sí parece prudente atender a las recomendaciones realizadas por los expertos y, en cualquier caso, propiciar una toma de decisiones compartida entre paciente y médico para determinar el momento de la administración de corticosteroides en relación con la de la vacuna frente a la COVID-19.

Las circunstancias individuales pueden requerir un corticosteroide fuera de la ventana recomendada, por lo que el análisis de riesgo/beneficio específico del paciente va a ser necesario.

\section{BIBLIOGRAFÍA}

1. Miller DC, Patel J, Gill J, Mattie R, Saffarian M, Byron DO, et al. Corticosteroid Injections and COVID-19 Infection Risk. Pain Med. 2020;21(8):1703-6. DOI: 10.1093/pm/ pnaa199.

2. Chakravarthy K, Strand N, Frosch A, Sayed D, Narra LR, Chaturvedi R, et al. Recommendations and Guidance for Steroid Injection Therapy and COVID-19 Vaccine Administration from the American Society of Pain and Neuroscience (ASPN). J Pain Res. 2021;14:623-9. DOI: 10.2147/JPR. S302115.

3. Lee H, Punt JA, Patel J, Stojanovic MJ, Duszynski BS, McCormick ZL. The Spine Intervention Society's Patient Safety Committee. Do Corticosteroid Injections for the Treatment of Pain Influence the Efficacy of Adenovirus Vector-Based COVID-19 Vaccines? Pain Med. 2021;22(6):1441-64. DOI: 10.1093/pm/pnab130.

4. Sytsma TT, Greenlund LK, Greenlund LS. Joint corticosteroid injection associated with increased influenza risk. Mayo Clin Proc Innov Qual Outcomes 2018;2(2):194-8. DOI: 10.1016/j.mayocpiqo.2018.01.005. 